Wilfrid Laurier University

Scholars Commons @ Laurier

Fall 2005

\title{
A Narrative Approach to the Evaluation of Supportive Housing: Stories of Homeless People Who Have Experienced Serious Mental Illness
}

\author{
Geoffrey Nelson \\ Wilfrid Laurier University, gnelson@wlu.ca \\ Juanne Nancarrow Clarke \\ Wilfrid Laurier University, jclarke@wlu.ca \\ Angela Febbraro \\ Wilfrid Laurier University \\ Maria Hatzipantelis \\ Wilfrid Laurier University
}

Follow this and additional works at: https://scholars.wlu.ca/psyc_faculty

Part of the Psychiatry and Psychology Commons, and the Sociology Commons

\section{Recommended Citation}

Nelson, Geoffrey; Clarke, Juanne Nancarrow; Febbraro, Angela; and Hatzipantelis, Maria, "A Narrative Approach to the Evaluation of Supportive Housing: Stories of Homeless People Who Have Experienced Serious Mental Illness" (2005). Psychology Faculty Publications. 13.

https://scholars.wlu.ca/psyc_faculty/13

This Article is brought to you for free and open access by the Psychology at Scholars Commons @ Laurier. It has been accepted for inclusion in Psychology Faculty Publications by an authorized administrator of Scholars Commons@ Laurier. For more information, please contact scholarscommons@wlu.ca. 


\section{A NarRative Approach to THE EVALUATION OF SUPPORTIVE HOUSING: STORIES OF HOMELESS People Who have EXPERIENCED SERIOUS MENTAL ILLNESS}

\author{
Geoffrey Nelson, Juanne Clarke, \\ Angela Febbraro \\ \& Maria Hatzipantelis
}

Geoffrey nelson, PhD, is Professor of PSYCHOLOGY AND A FACULTY MEMBER IN THE COMMUNITY PSYCHOLOGY PROGRAM AT WILFRID LAURIER UNIVERSITY.

Juanne Clarke, PhD, is Professor of SOCIOLOGY AND A FACULTY MEMBER IN THE COMMUNITY PSYCHOLOGY PROGRAM AT WILFRID LAURIER UNIVERSITY.

Angela Febbraro, PhD, was an ASSISTANT PROFESSOR OF PSYCHOLOGY AND A FACULTY MEMBER IN THE COMMUNITY PSYCHOLOGY PROGRAM AT WILFRID LAURIER UNIVERSITY. CURRENTLY, SHE IS A RESEARCH PSYCHOLOGIST WITH DEFENSE R \& D CANADA IN TORONTO.

MARIA HATZIPANTELIS, MA, IS A GRADUATE OF THE MA PROGRAM IN COMMUNITY PSYCHOLOGY AT WILFRID LAURIER UNIVERSITY.

THIS RESEARCH WAS SUPPORTED BY AN INTER-DISCIPLINARY RESEARCH GRANT FROM WILFRID LAURIER UNIVERSITY AND BY A GRANT FROM THE ONTARIO MINISTRY OF HEALTH AND LONG-TERM CARE (THROUGH THE ONTARIO MENTAL HEALTH FOUNDATION). WE WOULD LIKE TO THANK ROS SHIELDS AND JOHN RUSSELL FOR THEIR ASSISTANCE AND ALL OF THE PEOPLE WHO SHARED THEIR STORIES WITH US FOR THEIR PARTICIPATION IN THIS RESEARCH. THANKS ALSO TO NINA BAILEY-DICK FOR HER ASSISTANCE WITH ARRANGING AND CONDUCTING SOME OF THE INTERVIEWS.

CORRESPONDING AUTHOR: GEOFFREY NELSON, PHD DEPARTMENT OF PSYCHOLOGY WILFRID LAURIER UNIVERSITY WATERLOO, ON N2L $3 C_{5}$ CANADA

We present the findings of a narrative approach to the evaluation of supportive housing for formerly homeless people who have experienced serious mental illness. According to the accounts of 11 men and 9 women, their youth and adult years were filled with personal problems, troubled relationships, and a lack of adequate social resources. Since entering supportive housing, participants noted more stability in their lives and the beginning of journeys to recover positive personal identities, restore or develop new supportive relationships, and reclaim resources vital to leading lives with dignity and meaning. The findings add to the literature on housing interventions for this population in suggesting many positive gains beyond reductions in homelessness and hospitalization.

I

In Canada and the United States, people with serious mental illness have become particularly vulnerable to homelessness (Goering, Tolomiczenko, Sheldon, Boydell, \& Wasylenki, 2002; Rochefort, 1993). In response to this problem, different types of housing options have been created in some of the larger North American cities to serve people with serious mental illness (Parkinson, Nelson, \& Horgan, 1999). By now, several longitudinal, experimental and quasi-experimental studies have shown that when people are provided with decent housing and support, they are likely to continue to live in stable housing and stay off the streets and out of shelters and psychiatric settings (e.g., Goldfinger et al., 1999; Shern et al., 1997). However, quality of life outcomes have received little attention in these studies.
The purpose of this research was to determine whether the acquisition of stable housing is associated with improvements in social support, community integration, meaningful activity, and other aspects of quality of life of formerly homeless people with mental illness. To address this purpose, we used a qualitative approach to evaluation (Patton, 2002). Most of the evaluations of supportive housing for formerly homeless people with serious mental illness, as noted above, have used exclusively experimental and quantitative methods, with very few evaluations using qualitative methods (for an exception, see Parkinson \& Nelson, 2003).

A narrative approach to qualitative evaluation is particularly well suited to understanding the experiential realities of 
formerly homeless people (Boydell, Goering, \& Morrell-Bellai, 2000; Morrell-Bellai, Goering, \& Boydell, 2000). Narrative studies have been used by social and health scientists to understand people's experience of illness, trauma, and recovery in their interpersonal, social, and political contexts (Crossley, 2000; Murray, 1999; Nelson, Lord, \& Ochocka, 2001). Moreover, first-person accounts of psychiatric survivors' stories of recovery have also underscored the importance of both personal and contextual (including desirable housing) factors (e.g., Capponi, 2003).

Using a narrative approach, the main question that we addressed in this research was: What are the changes in the life stories and quality of life of people after they entered supportive housing compared with the time before they resided in supportive housing?

\section{Methodology}

\section{Housing Settings and Participants}

The provincial government of Ontario funded a mental health homelessness initiative that provided supportive housing for roughly 1,000 people living in Ontario's 3 largest cities (Toronto, Hamilton, Ottawa) who had been homeless and had experienced serious mental illness. There were a number of different types of supportive housing programs, including apartments rented from private owners, entire apartment buildings with individual units, and group living facilities with private and shared rooms. All programs had support staff who provided rehabilitation services, with some programs having on-site staff and some having staff who visited residents.

We conducted 18 interviews in Toronto and 2 in Hamilton with residents who had been living in one of these housing programs for at least a few months. We used a convenience sample that consisted of 11 men and 9 women, most of whom are white. The participants ranged in age from 29 to 59 , with most of the participants in their 40 s or 505 . Four of the participants lived in independent apartments, while the other 16 lived in group living residences. The settings vary in terms of physical comfort and privacy. Staff members at each of the settings organize various skill-building and recreational programs for the residents. Residents also received support from support workers from other agencies, and they are referred to and participate in numerous other programs.

\section{Interview Process}

The research team consisted of five people, four women (two M.A. community psychology candidates and two faculty members) and one man (a faculty member). The entire team participated in the initial set of 10 interviews which were conducted in one setting. All of the interviewers used the same semi-structured interview guide, and all participants were given an honorarium of $\$ 15$. The remaining 10 interviews were conducted at different settings by pairs of interviewers.

\section{Data Analysis and Feedback Process}

All of the interviews were audiotaperecorded and transcribed. Research team members read all of the interview transcripts and met to discuss their impressions and emerging codes and themes. We focused primarily on 15 of the interviews, since five of the participants were either too symptomatic or had neurological or memory problems that made it difficult for them to relate a coherent story.

After initial discussions about the interviews, we settled on a framework for completing the data analysis. We used a matrix display with two dimensions (Miles \& Huberman, 1994). The first dimension is the time period of each person's life, with two broad periods used for this paper: the youth and adult years and the period after entering supportive housing. The second dimension consists of three broad themes: personal issues, relationships, and resources. We initially came up with a larger number of codes for this second dimension (e.g., improved health, improved selfesteem). We found that these initial codes could be grouped into a smaller number of overarching themes (e.g., personal issues, relationships, and resources). Using this coding template, we divided the interviews among team members and recoded each transcript. In addition to this coding process, one of the team members constructed short (1-2 page) summaries of each of the 20 stories. We did not use these summaries for the data analysis, but rather for feedback purposes. We sent each participant the summary of his or her story, along with an overall summary of the research findings. A longer technical report was sent to staff of the housing programs.

\section{Findings}

The findings are organized into two periods of time: the person's youth and adult life before supportive housing and their life after supportive housing.

\section{Youth and Adult Life}

Taken as a whole, the youth and adult lives (before supportive housing was obtained) of the individuals with whom we spoke were filled with personal health issues, unsupportive relationships, and few stable resources to build upon.

Personal. In terms of personal wellbeing, participants described issues with alcoholism, mental health, and physical health. Several described the severity of their addiction to alcohol.

I was living by myself and I was drinking. After a couple of years of drinking I was told that if I didn't quit I would be dead in 2 years. I was drinking 25 years up 
until 2, 4 years ago...And as I say, I wasn't drinking 25 months and I started drinking again and it wasn't a week before I was back in the hospital. My memory was even worse after that.

Moreover, participants described the difficulties associated with trying to understand their mental illness and receive a diagnosis and support.

I was messed up mentally back then but nobody knew it then. I didn't even know myself....People didn't talk about depression back then....I think I had it all through grade school too.

Relationships. It was evident from the interviews that participants often characterized their marriages, families, and social lives as unsupportive.

[I was married] on and off for 2 years.... And I never remarried. He was very abusive.

My brother-in-law, my sisters, my nephew, there is something about them. I just can't seem to get along with them. It's been my choice for many years to stay away from them.

Yet, there were instances in which the families and spouses of participants had played a supportive role in their youth and adult lives and continued to do so.

I had a great family. My parents have a strong marriage..... It was a good environment to grow up in.

And I still have some love for my exwife. I still put her on a pedestal. She was the greatest thing.... That was a turning point too, getting married.

The pattern of poor quality relationships was also evident in participants' relationships with other people.

My total life, I had no social life, no friends, so I drifted that way.

On the other hand, not all the relationships that participants had with other people were unsupportive.
I also found a boss that cared about me, that made me feel comfortable. I never thought that he would fire me or let me go like the other places.

A prevalent theme in the data was that participants experienced repeated cycles of victimization in their lives which ranged from physical abuse, to theft, and finally to rape:

I came back to search for my father and had DNA tests done. When my parents died, the ones that adopted me, they ran an article in the paper about that I was abandoned as a baby and...if anyone knew anything would they please call Parent Finders. And this person phoned me, and I never believed they were my father and there was a fairly large inheritance involved and he kept pressing me for money. And he came to live with me and I thought he was my father and he raped me and just took advantage of everything. Finally I got away from that...I got out [of jail] last year and I had 2 weeks to move into the apartment. Well, the man that was in the rooming house was always over at my place, that I met at the rooming house and I told him that he would have to get out too, because that apartment was for me... He just turned on me one night and grabbed me and assaulted me and he held me prisoner for 2-3 days and I really couldn't move...So finally I escaped one morning.

Resources. Consistent with the history of relationships that offered little support, participants did not have many tangible resources to rely upon in terms of stable housing, employment, or education. Participants shared stories of homelessness and inadequate or unstable housing:

I moved into this house that was a hole. And then when I moved out of there I went to the [shelter] but I didn't want to stay there anymore (there were lots of drugs there, cockroaches and cats!).
Additionally, participants also noted that they did not have steady employment during their lives and that at times it was difficult to keep a job:

So I went to work, and I was drinking more and more and I started drifting from job to job, and I was withdrawn. Well I was drifting...I would be out of work for awhile, then I would go to another job. So I had periods when I was broke.

Yet, we also heard stories of good work experiences during one's adult life:

I was a salesman...for about 14 years or longer, then I went to the transit company.

Many participants had little formal education because they did not complete high school.

\section{After Supportive Housing}

Personal. Overall, the participants conveyed a more positive sense of their lives since having entered supportive housing, compared to the conditions of their earlier youth and adult lives. Participants described greater feelings of independence and well-being, the development of strengths, and a better vision for the future.

I am really happy because now I am living on my own...I pay $\$ 414 /$ month, which is manageable...and I have a car...[I have] more control. So I like it a lot better.

Yeah, I feel better. Big time [compared to when I was out on the street].

Participants talked about how being in supportive housing helped them to stay out of jail, and to cease, or at least control, their substance addictions:

Well, it [supportive housing] has kept me out of jail for a year...And I don't shoplift anymore and they got me on the right medication...I can't say anything higher about the program...Oh, it is wonderful...This is the best my life has ever been. 
Relationships. Overall, there was a positive change in the quality of relationships that participants had with people after entering supportive housing. The friendliness and supportiveness of housing staff was a common theme in the narratives of participants:

$$
\begin{aligned}
& \text { I like the staff here...They are nice. [I } \\
& \text { trust them.] } \\
& \text { Well, I had lots of help from...support } \\
& \text { you know...from the staff that run [the } \\
& \text { housing program] through [an agency]. } \\
& \text { And if I had a problem I would just call } \\
& \text { them and they would come over and } \\
& \text { help me. And they would drive me } \\
& \text { places and they helped me get my } \\
& \text { furniture. }
\end{aligned}
$$

Support from case workers from outside the housing program was also mentioned as important:

It's good. I got three workers. One out in the community and helps with medicine. I go there on Thursdays and he comes to see me on Wednesdays...Just one is my worker from the work I do, and one worker does just support and they want me to get involved with some things during the day, keep myself busy.

Participants spoke of positive changes in their social lives since moving into supportive housing. People talked about making friends with other residents, for example:

\section{Before supportive housing -}

I was living on my own in boarding houses. But I didn't get along with nobody. Well they picked on me, you know.

\section{After supportive housing -}

Well, you know, going out with people and talking to them and that stuff... I've made friends here [at this housing program].

Although we were struck by the lack of family support in participants' lives, par- ticipants also spoke about the importance of maintaining family connections.

And the only person that I see in my family is my mother. And she lives a block away from me... We see each other almost every day. I talk to her every single day, a couple times in the day. I get along with her...I have always gotten along with her. I love her very much. She loves me...It doesn't matter what kind of life I have, she will always be there for me.

Resources. We found that supportive housing provided participants with practical resources in their lives, related to their neighborhood; safety; having stable housing (e.g., food, clothing, affordability); the overall quality of their housing; opportunities for recreation; opportunities for work, meaningful activities, and community participation; access to transportation; and privacy issues. In addition, participants commented on general independence issues and on whether they felt that their current housing provided them with an overall good fit.

Participants who talked about safety issues spoke of how much safer they felt since having moved into their current supportive housing:

The place I am living now...I like it. There are no drug dealers or things like that...Yeah. [I feel safe.] I feel comfortable.

Still, one individual told us that she did not feel safe in her current living environment, although this may be more directly related to that individual's feelings of pain:

No [I do not feel safe here]. I am just too much in pain to even think about it. I told my social worker I am upset about this place.

Participants also talked about the benefits of having stable housing, a roof over one's head, good food and better clothes:
My social worker found someone to reduce my rent...you can eat better, you can dress better. That's what I have been doing...I wear better clothing, things like that...I eat better. I buy shoes, clothing...It'll help me in the long run, too...Well, maybe save more money for the future. Being able to put more money in the bank. In case of an urgent matter, things like that...And maybe offer my mother something for what she has done for me...My life is more stable.

In several cases, participants stated that they felt that their current housing was the best housing they have ever lived in:

This has been a godsend really...This is perfect. This is the best housing I have ever had.

Still, despite such glowing testimonials, participants expressed concerns over the quality of their current housing.

The apartment looked okay, but it has n't been ideal here. In March sometime, I got flooded. The sewer backed up...And I could have been electrocuted because I have these power bars on the floor...It hadn't risen enough to get to the plugs yet...It was all sewer water, not very nice... There is also a lot of cockroaches in this place.

Opportunities for work and other meaningful activities, such as community participation, were also mentioned as valued aspects of their current housing situations:

I have three jobs now...I clean the grounds [of apartment buildings] or I help [a worker] clean the apartments...or help restore the place...just when it needs to be done....Monday, Wednesday and Fridays is when I go to work. Three and half hours a day.

Participants specifically mentioned the benefits that being able to work or vol- 
unteer has brought to their lives, such as self-esteem and a sense of purpose:
Plus, it is good for my self-esteem to work anyway...I want to work if I possi- bly can....Because of my illness and everything and my community spirit I did a lot of, I worked on a lot of Board of Directors [for a community kitchen/ drop-in centre, a housing agency, and another housing agency]...I coached PeeWee baseball for a few years.

The final few resources that we focus on here include privacy issues, broader independence issues, and the extent to which participants believed that their current housing situation provided them with a good overall fit in their lives. Concerning privacy, participants reported that they experienced more privacy in their current housing arrangement than in previous housing situations, and this factor seemed to be very important to their enjoyment of their homes:

\section{The reason I like this place [housing program] is that you got your own room...When you share a room [people steal things from you].}

Still, not everyone reported more privacy in their current housing:

I don't like the sharing of rooms. That is the only thing I do not like...I like everything about [this place]. Except I don't like sharing a room. [Single rooms] would be the only thing to make it better.

Also, participants spoke of a negative outcome of supportive housing, that of a loss of personal independence:

A rude awakening from having your own apartment to here and other people looking after you and feeding you and stuff...I was always used to doing things for myself all the time, now I got them all done basically.

This desire for privacy, and also independence, is further illustrated by the comment of one participant, who lacks the economic resources to fulfill his goal of being on his own again:

I've been looking for my own place for the last little while. I want to be on my own again...Well, it all comes down to money.

Finally, the importance of finding housing that represents a "good fit," that provides a sense of belonging with the other residents, and thus a sense of community, was also expressed by one participant, who unfortunately has not found that sense of fit in his current housing:

I stick to myself, because I don't really have nothing in common with most of the people here.

\section{Discussion}

The goal of this research was to examine changes in the life stories and quality of life of people after they entered supportive housing compared with the time before they resided in supportive housing. Overall, participants described major improvements in their quality of life. Participants described positive personal changes, such as a sense of increased independence and improved well-being since their move. They also stated that the quality of their relationships had improved.

Participants said that they were able to maintain some contact with at least one family member; usually they described themselves as getting along with the staff in the housing units; and most were making friends and experienced little interpersonal conflict in their new housing. Participants believed that their lives were more stable, and that they had better access to resources, such as food and clothing. Those who had independent apartments or single rooms experienced increased privacy. Some people were happy with and felt safe in the neighborhoods in which they were housed, while others did not feel safe going out at night. Participants mentioned that they were pleased to be engaged in meaningful activities, including paid and volunteer work in their present housing circumstances.

Previous quantitative evaluations of supportive housing for formerly homeless people with serious mental illness have focused on the reduction of time spent homeless and in institutions, not changes in residents' quality of life (e.g., Goldfinger et al., 1999; Shern et al., 1997). The findings of the present study suggest that people who get access to supportive housing also benefit in many other ways. Thus, the findings of this qualitative research provide direction for future quantitative research in terms of the need to examine changes in measures of quality of life using longitudinal designs with comparison groups.

The high level of satisfaction with the housing reported by our participants could have resulted from positive experiences. Narrative research with people with serious mental illness who have moved into more independent housing, but who have no history of homelessness, has revealed very similar themes to those in this study (Parkinson \& Nelson, 2003). Then again, the positive changes that participants reported may have been the result of the very low expectations they had learned to have for their lives as a result of their long-term mental health problems, adjustment to poor living conditions, their lack of knowledge of alternatives, their compliance with professional treatment regimens, or a diminished sense of entitlement and autonomy or choice, as Boydell, Gladstone, Crawford, and Trainor (1999) have suggested.

The high level of satisfaction could also relate to participants' beliefs that we were in some way or another "in cahoots" with the staff, government and 
managers. In this context participants may not have felt free to honestly express their ambivalence or criticism because they may have identified us as having "power" who could affect their current situation. Goffman (1959) used the term "impression management" to convey the idea that we all interact such that we try to manage the impressions that others have of us. The participants may have been presenting themselves in as positive a light as they could, building on their knowledge of desired norms and values of the dominant society and wanting to please us.

Participants expressed many signs of hope. Having hope has been found to be an important part of recovery stories of people with serious mental illness (Kirkpatrick, Landeen, Woodside, \& Byrne, 2001). Building on the work of Kathy Charmaz (1994) on identities after illness, Boydell et al. (2000) noted that the homeless people with whom they spoke reflected on future selves. Clearly many of the people in our sample did as well. They spoke of finding work, looking for their own place, saving money, giving money to others, being promoted from a client to a volunteer, offering support to a mother. Despite the troubled child and adult selves described by the participants, they maintained hope that the future would be better. Indeed, the frameworks in which hope resided were those that are socially and culturally supported-work, money, saving and helping others.

We also noticed that the housing settings differed with respect to cleanliness, privacy, presence of an in-room bathroom, neighborhood convenience, quiet, safety, and the aesthetic quality of both the inside and the outside of the physical structures. Previous research has found that these qualities are all important features of supportive housing that are related to residents' quality of life (Parkinson et al., 1999). For the most part we were unable to relate outcomes to these housing characteristics, due to the small sample size. One exception is that of privacy. We found that those participants who shared rooms voiced less satisfaction with their housing than those who had their own rooms.

In conclusion, we believe that while the supportive housing initiative is not perfect, it is a step in a positive direction that has increased participants' quality of life in terms of their physical and mental health, their sense of independence, and their participation in the community. The quality of life outcomes were positive for the participants in this study, but there were still shortcomings in the quality of some of the housing. Moreover, the amount of housing created through this mental health homelessness initiative is insufficient, as there continues to be many homeless people in major Ontario cities (Caragata, 2003). The 1,000 units of housing that were created in Ontario in 2001 as a result of the Phase I mental health homelessness initiative are a "drop in the bucket" compared with the 25,000 new units of governmentfunded affordable housing that were created in Canada in 1980. Moreover, while the provincial and federal governments made an agreement in 2001 to share the costs of new social housing, the Ontario government has not only not paid its share, it has actually cut spending on social housing since the time of this agreement (National Housing and Homelessness Network, 2003). Given the benefits of supportive housing reported by participants in this study, we believe that government policy should expand housing options for people with serious mental illness who have been homeless, mandate non-shared rooms, and ensure minimal standards of physical quality of the housing. No one should go homeless or live in substandard housing.

\section{References}

Boydell, K. M., Gladstone, B. M., Crawford, E., \& Trainor, J. (1999). Making do on the outside: Everyday life in the neighborhoods of people with psychiatric disabilities. Psychiatric Rehabilitation Journal, 23(1), 11-18.

Boydell, K. M., Goering, P., \& Morrell-Bellai, T. L. (2000). Narratives of identity: Re-presentation of self in people who are homeless. Qualitative Health Research, 10, 26-38.

Capponi, P. (2003). Beyond the crazy house: Changing the future of madness. Toronto: Penguin.

Caragata, L. (2003). Housing and homelessness. In A. Westhues (Ed.), Canadian social policy: Issues and perspectives (3rd Ed.) (pp. 67-89). Waterloo, ON: Wilfrid Laurier University Press.

Charmaz, K. (1994). Discoveries of self in illness. In M. L. Dietz, R. Prus, \& W. Shaffir (Eds.), Doing everyday life: Ethnography as human lived experience (pp. 226-242). Mississauga, ON: Copp Clark Longman Ltd.

Crossley, M. L. (2000). Narrative psychology, trauma, and the study of self/identity. Theory and Psychology, 10, 527-546.

Goering, P., Tolomiczenko, G. S., Sheldon, T., Boydell, K., \& Wasylenki, D. (2002). Characteristics of persons who are homeless for the first time. Psychiatric Services, 53, $1472-1474$.

Goldfinger, S. M. Schutt, R. K., Tolomiczenko, G. S., Seidman, L., Penk, W. E., Turner, W., \& Caplan, B. (1999). Housing placement and subsequent days homeless among formerly homeless adults with mental illness. Psychiatric Services, 50, 674-679.

Goffman, I. (1959). The presentation of self in everyday life. New York: Anchor.

Kirkpatrick, H., Landeen, J., Woodside, H., \& Byrne, C. (2001). How people with schizophrenia build their hope. Journal of Psychosocial Nursing and Mental Health Services, 39, 46-53.

Miles, M. B., \& Huberman, A. M. (1994). Qualitative data analysis: An expanded sourcebook (2nd Ed.). Thousand Oaks, CA: Sage.

Morrell-Bellai, T., Goering, P., \& Boydell, K. (2000). Becoming and remaining homeless: A qualitative investigation. Issues in Mental Health Nursing, 21, 581-604. 
Murray, M. (1999). The storied nature of health and illness. In M. Murray \& K. Chamberlin (Eds.), Qualitative health psychology: Theories and methods (pp. 47-63). London: Sage.

National Housing and Homelessness Network. (April 15, 2003). More than half provinces betray commitments: NHHN "report card" shows few new units 17 months after housing deal signed. Available from Housing Again, http://www.housingagain.web.net/.

Nelson, G., Lord, J., \& Ochocka, J. (2001). Empowerment and mental health in community: Narratives of psychiatric consumer/survivors. Journal of Community and Applied Social Psychology, 11, 125-142.

Parkinson, S., \& Nelson, G. (2003). Consumer/survivor stories of empowerment and recovery in the context of supported housing. International Journal of Psychosocial Rehabilitation, 7, 103-118.

Parkinson, S., Nelson, G., \& Horgan, S. (1999). From housing to homes: A review of the literature on housing approaches for psychiatric consumer/survivors. Canadian Journal of Community Mental Health, 18(2), 145-164.

Patton, M. Q. (2002). Qualitative research and evaluation methods (3rd ed.). Thousand Oaks, CA: Sage,

Rochefort, D. A. (1993). From poorhouses to homelessness: Policy analysis and mental health care. Westport, CT: Auburn House.

Shern, D. L., Felton, C. J., Hough, R. L., Lehman, A. F., Goldfinger, S., Valencia, E., Dennis, D., Straw, R., \& Wood, P. A. (1997). Housing outcomes for homeless adults with mental illness: Results from the second-round McKinney program. Psychiatric Services, 48, 239-241.
A Comprehensive Guide for Integrated Treatment of People with Co-Occurring Disorders

Edited by Diane Doyle Pita \& LeRoy Spaniol

\section{Contents:}

Parameters and Course of Disorders

Assessment - Treatment - Cognitive-Behavioral Approaches

Clinical Issues - Role Recovery • Family and Self-Help Support Legal System Involvement

2002, 792 pages, ISBN: 1-8785/2-12-9

$\$ 69.95$ plus shipping (see below). People with psychiatric disabilities and their families are eligible for a $40 \%$ discount ( $\$ 41.97$ per copy plus shipping as indicated below).

Shipping costs: For a single copy add $\$ 5$ for domestic shipping or $\$ 10$ for Alaska, Hawaii, Canada, or international shipping. If ordering multiple copies please call or e-mail for shipping costs.

Name

Organization

Street Address

\begin{tabular}{lcc}
\hline City & State & Zip \\
\hline Phone & Fax \\
\hline E-mail & Country \\
\hline
\end{tabular}

- Please send ___ copies of A Comprehensive Guide for Integrated Treatment of People with Co-Occurring Disorders

- Enclosed is a check or money order payable to Boston University. (Payment must be in U.S. funds by U.S. bank draft or international money order.)

- Please charge my credit card:

_ VISA _ MasterCard _ Discover Card

Card Account Number

Expiration Date

Signature of Authorized Buyer

Mail or fax your order with payment to:

Center for Psychiatric Rehabilitation, Boston University 940 Commonwealth Avenue West, Boston, MA 02215

Phone: 617/353-3549 Fax: 617/353-9209

\section{Order online at http://www.bu.edu/cpr/}

